\title{
Pancreatic Acinar Cell Cystadenoma
}

National Cancer Institute

\section{Source}

National Cancer Institute. Pancreatic Acinar Cell Cystadenoma. NCI Thesaurus. Code C95546.

A benign, cystic acinar cell neoplasm that arises from the exocrine pancreas. The cysts are lined by well-differentiated cells which show acinar differentiation. 